Revista de Derecho Público: Teoría y Método Marcial Pons Ediciones Jurídicas y Sociales

Vol. 1 | 2020 pp. 7-28 Madrid, 2020

DOI:10.37417/RPD/vol 2202032

(C) Flavio Quezada

ISSN: $2695-7191$

Recibido: 20/12/2019 | Aceptado: 12/03/2020

Editado bajo licencia Creative Commons Attribution 4.0 International License.

\title{
UNA APROXIMACIÓN CRÍTICA A LA COMPARACIÓN DE DERECHOS ADMINISTRATIVOS
}

\section{A CRITICAL APPROACH TO THE COMPARISON OF ADMINISTRATIVE LAWS}

Flavio Quezada

Universidad de Barcelona

RESUMEN: El presente trabajo se propone elaborar un conjunto de herramientas metodológicas que resulten útiles para la comparación de derechos administrativos, adoptando una perspectiva crítica en un triple sentido: desde el pensamiento crítico, desde el comparatismo crítico y desde una aproximación crítica al derecho administrativo, en tanto objeto de estudio para la comparación. Para seguir este camino se requiere exponer brevemente la discusión epistemológica entre el funcionalismo y el comparatismo crítico; luego aproximarse críticamente a los discursos sobre la convergencia de derechos en el contexto de la globalización neoliberal. Estos pasos permiten justificar la importancia de estas comparaciones como identificar el objeto de comparación. Posteriormente, se elaboran cinco herramientas metodológicas cuya articulación concreta dependerá de los fines específicos de la investigación.

PALABRAS CLAVE: Derecho comparado; Derecho Administrativo; Teoría Crítica; Metodología.

ABSTRACT: The present work aims to develop a set of methodological tools that are useful for the comparison of administrative laws, adopting a critical perspective in a triple sense: critical thinking, critical comparative law and a critical approach to administrative law, as a subject of study for comparison. In order to follow this path, it is necessary to briefly present the epistemological discussion between functionalism and critical comparative law; and then critically approach

* Esta investigación se desarrolló gracias al financiamiento de la Agencia Nacional de Investigación y Desarrollo de la República de Chile (CONICYT PFCHA/DOCTORADO BECAS CHILE/2018 $-72190220)$. 
the discourses on the convergence of laws in the context of neoliberal globalization. These steps allow us to justify the importance of these comparisons as well as to identify the object of comparison. Subsequently, five methodological tools are developed, the particular articulation of which will depend on the specific purposes of the research.

KEYWORDS: Comparative Law; Administrative Law; Critical Theory; Methodology.

SUMARIO: 1. INTRODUCCIÓN-2. LA CRÍTICA AL COMPARATISMO TRADICIONAL.

2.1. El funcionalismo de Konrad Zweigert y Hein Kötz. 2.2. La crítica del comparatismo crítico. 2.3. La especificidad de la comparación de derechos administrativos-3. HERRAMIENTAS METODOLÓGICAS PARA COMPARAR DERECHOS ADMINISTRATIVOS. 3.1. El factor biográfico: de la deconstrucción a la reconstrucción de sí. 3.2. Herramientas para la construcción ad hoc de un espacio de comparación. 3.2.1. Herramienta uno: deconstrucción y reconstrucción contextualizada del Derecho extranjero. 3.2.2. Herramienta dos: justificación de la selección de casos. 3.2.3. Herramienta tres: considerar la trampa del lenguaje. 3.2.4. Herramienta cuatro: el tracing de textos. 3.2.5. Herramienta cinco: la conceptualización y la comparación conceptual. 3.3 Los fines de la comparación de derechos administrativos-4. CONCLUSIÓN

\section{INTRODUCCIÓN}

Es un lugar común en la literatura especializada señalar que el Derecho público, por razones prácticas e históricas, no habría ocupado un lugar central en la producción intelectual del comparatismo. En efecto, se afirmaba que resultaría imposible desarrollar investigaciones comparativas satisfactorias sobre los Derechos públicos, debido a su complejidad y asistematicidad, producto del marcado carácter nacional de un derecho expresión directa de la conflictividad política ${ }^{1}$.

Lo anterior usualmente es matizado mediante el argumento histórico que remonta los orígenes del comparatismo a autores griegos clásicos, tales como Heródoto, Platón y Aristóteles ${ }^{2}$, que se habrían ocupado de asuntos que hoy vincularíamos al Derecho político o constitucional, como, en especial, por el rol fundador del Derecho constitucional comparado que se le asigna a Montesquieu ${ }^{3}$. Sin embargo, en la actualidad, un argumento particularmente influyente, ha sido intentar refutar la incomparabilidad del Derecho público, negando su especificidad nacional, lo cual

1 Jean RIVERO, "Le droit administratif en droit comparé: rapport final", Revue internationale de droit comparé, vol. 41, núm. 4, 1989, pp. 919-926 (pp. 919-921). François HAUT, "Réflexion sur la méthode comparative appliquée au droit administratif", Revue internationale de droit comparé, vol. 41, núm. 4, 1989, pp. 907-914. Giacinto DELLA CANANEA, "Administrative Law in Europe: A historical and comparative perspective", Italian Journal of Public Law, vol. 2, núm. 2, 2009, pp. 162-211 (pp. 167-169). Janina BOUGHEY, "Administrative law: The next frontier for Comparative Law", International and Comparative Law Quarterly, vol. 62, 2013, pp. 55-95 (pp. 57-60).

2 Marie-Claire PONTHOREAU, Droit(s) constitutionnel(s) comparé(s), Economica, Paris, 2010, p. 33. Susana DE LA SIERRA, Una metodología para el Derecho Comparado Europeo, Derecho Público Comparado y Derecho Administrativo Europeo, Thomson Civitas, Madrid, 2004, p. 72.

${ }_{3}$ Marie-Claire PONTHOREAU, op. cit., p. 34. 
se reflejaría en un fenómeno de convergencia jurídica, sea a nivel global en tanto expresión de la globalización jurídica ${ }^{4}$, como a nivel europeo, en la denominada europeización del Derecho público ${ }^{5}$. En este contexto, sería el Derecho constitucional comparado el que destacaría, por su numerosa producción intelectual en las décadas recientes, que incluso lleva a algunos a afirmar un cierto giro del comparatismo desde el iusprivatismo hacia el iuspublicismo, cuyo centro estaría en dicha área ${ }^{6}$. El correlato de esta afirmación sería el rol secundario, incluso pintoresco, de emprender comparaciones de Derecho administrativo ${ }^{7}$. Así, si bien ya no se trataría de una empresa imposible, sería, a lo menos, de poca relevancia.

El presente trabajo pretende recorrer un camino alternativo a partir de las preguntas que permite formularse el pensamiento crítico y su expresión en el comparatismo, desde esa base teórica, se justificará la posibilidad de comparar Derechos administrativos y su importancia. Se trata de tomar en serio a dicha corriente, no descartarla, de entrada, por ser, supuestamente, demasiado radical. Esta tarea resulta de relevancia, puesto que lo que la caracteriza es seguir nuevos caminos de reflexión, cuestionar los supuestos asentados, desnaturalizar lo que pareciera ser obvio o incuestionable; todo lo cual resulta particularmente importante cuando se trata de aproximarse a la otredad jurídica, ya que normalmente quien utiliza el Derecho extranjero en una discusión jurídica o política interna, como quien emprende comparaciones, "no dice todo lo que hace" ${ }^{8}$, y la posibilidad de que exista tras ello un uso ideológico implícito, consciente o inconsciente, estará siempre presente.

En la reflexión que propone este trabajo, la comparación jurídica implicará un proceso de cuestionamiento tanto del propio comparatista, de la doxa dominante en los casos que desea estudiar, como de los discursos elaborados en las discusiones entre comparatistas. Ello permitirá a quien emprenda esta tarea no solo una mejor comprensión del fenómeno jurídico, sino de la propia expresión que adopta en el medio en el cual se desenvuelve.

Cabe precisar que, siguiendo a Rivero, se prefiere la expresión "comparación de Derechos administrativos" y no "Derecho administrativo comparado", puesto que,

${ }^{4}$ Jean-Bernard AUBY, La globalisation, le droit et l'État, LGDJ, Paris, 2a ed., 2010. Jean-Bernard AUBY, "Globalisation et Droit Comparé, European Journal of Law Reform, vol. 8, núm. 1, 2006, pp. 43-52.

5 Thorsten SIEGEL, Europeización del Derecho Público. Marco de condiciones y puntos de interacción entre el Derecho europeo y el Derecho (administrativo) nacional, Marcial Pons, Madrid, 2016. Jürgen SCHWARZE, "Towards a Common European Public Law", European Public Law, vol. 1, núm. 2, 1995, pp. 227-239. Jürgen SCHWARZE, "The Convergence of the Administrative Laws of the EU Member States", European Public Law, vol. 4, núm. 2, 1998, pp. 191-210. Jürgen SCHWARZE, "Enlargement, the European Constitution, and Administrative Law", International and Comparative Law Quarterly, vol. 53, 2004, pp. 969-984.

${ }^{6}$ Etienne PICARD, "La comparaison en droit constitutionnel et en droit administratif du droit comparé comme méthode au droit comparé comme substance", Revue internationale de droit comparé, vol. 67, núm. 2, 2015, pp. 317-329 (p. 317).

7 Ibid., p. 318.

8 Marie-Claire PONTHOREAU, op. cit., p. 100. 
tal como dicho autor explica, "[la] comparación implica pluralismo: el Derecho comparado es la comparación de diversos Derechos" ${ }^{9}$. Esta precisión no solo resultó adelantada para su tiempo, sino que permite, a su vez, evidenciar uno de los argumentos centrales del comparatismo crítico: el hecho o, incluso, el valor de la diferencia.

Así, asumiendo las limitaciones propias de todo proyecto intelectual, como de la reflexión jurídica en particular, se intentará elaborar una propuesta que permita comparar Derechos administrativos de una forma crítica, a lo menos, en tres sentidos: primero, teniendo como trasfondo teórico el pensamiento crítico ${ }^{10}$; segundo, adscribiendo al comparatismo crítico; y, tercero, aproximándose críticamente al Derecho administrativo ${ }^{11}$ en cuanto objeto de comparación. Se asume que tanto el Derecho comparado como el Derecho administrativo son espacios de disputa epistémica entre diversos discursos jurídicos concurrentes, en el sentido que Ponthoreau lo plantea respecto del primero ${ }^{12}$ y Caillosse respecto del segundo ${ }^{13}$.

Para desarrollar aquello se seguirá un curso argumental en dos tiempos: primero, se expondrá la discusión epistemológica entre el comparatismo tradicional y el comparatismo crítico, para evidenciar la crítica al comparatismo tradicional; para luego, como consecuencia de lo anterior, presentar una propuesta metodológica. Se cerrará el trabajo con una conclusión que se siga de lo expuesto.

\section{LA CRÍTICA AL COMPARATISMO TRADICIONAL}

Como explica Rambaud, la denominada escuela funcional del Derecho comparado tiene sus orígenes en destacados juristas alemanes, tales como Rabel, Rheinstein,

9 Jean RIVERO, op. cit., p. 925.

10 Razmig KEUCHEYAN, Hémisphère gauche, Une cartographie des nouvelles pensées critiques, La Découverte, 2017, $3^{a}$ ed., Paris. Étienne BALIBAR, La philosophie de Marx, La Découverte, Paris, 2014. Jaime BASSA, Constituyentes sin poder, una critica a los limites epistémicos del derecho moderno, EDEVAL, Valparaíso, 2018. Michel MIAILLE, Une introduction critique au droit, François Maspero, Paris, 1976. Emmanuel JEULAND, Théorie relationiste du droit. De la French Theory à une pensé européenne des rapports de droit, LGDJ, Paris, 2016. François CUSSET, French Theory. Foucault, Derrida, Deleuze \& cia et les mutations de la vie intellectuelle aux États-Unis, La Découverte, Paris, 2005. Henri LEFEBVRE, Hegel, Marx, Nietzsche (o el reino de las sombras), Editorial Siglo XXI, Madrid, 2016. Göran THERBORN, La ideología del poder y el poder de la ideología, Editorial Siglo XXI, Madrid, 2015. Jacques DE VILLE, "Rethinking Power and Law: Foucault's Society must be Defended", International Journal for the Semiotics of Law, vol. 24, 2011, pp. 211-226. Zia AKHTAR, "Law, Marxism and the State", International Journal for the Semiotics of Law, vol. 28, 2015 (pp. 661-685).

${ }^{11}$ Daniel MOCKLE, "Les aproches critiques du droit administratif", Les Cahiers de droit, vol. 57, núm. 3, 2016, pp. 497-526.

${ }_{12}$ Marie-Claire PONTHOREAU, "Trois interprétations de la globalisation juridique, Approche critique des mutations du droit public", L'Actualité Juridique Droit Administratif, núm.1, 2006, pp. 20 25. En especial en: Marie-Claire PONTHOREAU, "'Global Constitutionalism'. Un discours doctrinal homogénéisant, Lapport du comparatisme critique”, Jus Politucum, núm. 19, 2018, pp. 105-134.

13 Jacques CAILLOSSE, La constitution imaginaire de l'administration, Presses Universitaires de France, Paris, 2008, pp. 231-321. Jacques CAILLOSSE, L'État du droit administratif, LGDJ, Paris, 2017, pp. 15-28. 
Schlesinger, Zweigert y Kötz ${ }^{14}$. Sin embargo, son los dos últimos quienes gozan de mayor influencia en los trabajos comparativos actuales, lo cual puede apreciarse en las abundantes citas que se realizan a su obra, traducida al castellano como "Introducción al Derecho Comparado", como, en especial, en la aplicación explícita o implícita de sus postulados metodológicos. Esta episteme hegemónica en los círculos académicos del comparatismo ha sido ácidamente cuestionada en sus supuestos implícitos, como en sus consecuencias no evidenciadas, por una corriente crítica cuyos hitos más relevantes pueden remontarse a dos momentos: el trabajo de Frankenberg y la crítica de Legrand. Las posibilidades teóricas abiertas por este embate son asumidas tempranamente por Ponthoreau y luego aquilatadas en su obra más relevante. Cabe advertir que no se abordará un desarrollo acabado ni lineal de la discusión teórico-metodológica del Derecho comparado, puesto que ha sido abordado por otros trabajos en forma detallada ${ }^{15}$.

La discusión teórico-metodológica no ha estado ausente en el medio hispanohablante, así, por ejemplo, Tawil, en los parámetros tradicionales explica su utilidad para el derecho público interno desde el medio académico argentino ${ }^{16}$; De la Sierra, con una perspectiva bastante actualizada sintetiza los problemas más relevantes en su libro sobre el tema, lo cual es actualizado en un reciente artículo ${ }^{17}$; y Velasco, en una perspectiva que bien podría entroncarse con el funcionalismo, desarrolla una metodología comparativa para el derecho administrativo ${ }^{18}$.

Esta sección se subdividirá en tres: la primera, que sintetizará la propuesta teórico-metodológica del funcionalismo; la segunda, en la cual se exponen las objeciones realizadas por el comparatismo crítico; y, la tercera, que contiene ciertas consecuencias que se siguen de lo anterior. Estos tres pasos permitirán, en la segunda sección, elaborar una propuesta metodológica.

\subsection{El funcionalismo de Konrad Zweigert y Hein Kötz}

La obra de Zweigert y Kötz titulada como una simple introducción dista mucho de limitarse a ello, puesto que no solo ahonda en la comparación de diversas insti-

14 Thierry RAMBAUD, Introduction au droit comparé, Les grandes traditions juridiques dans le monde, Presses Universitaires de France, Paris, 2017, pp. 24-25.

${ }^{15}$ Béatrice JALUZOT, "Méthodologie du droit comparé: bilan et prospective", Revue internationale de droit comparé, vol. 57, núm. 1, 2005, pp. 29-48. Jaakko HUSA, "Methodology of comparative law today: from paradoxes to flexibility?", Revue internationale de droit comparé, vol. 58, núm. 4, 2006, pp. 1095-1117. Hiram CHODOSH, "Comparing Comparisons: In Search of Methodology", Iowa Law Review, núm. 84, 1999, pp. 1025-1131.

${ }^{16}$ Guido TAWIL, "El estudio del derecho comparado y su incidencia en el desarrollo del derecho público interno", $A F D U D C$, núm. 13, 2009, pp. 819-830.

17 Susana DE LA SIERRA, op. cit. Susana DE LA SIERRA, "Limites y utilidades del derecho comparado en el derecho público. En particular, el tratamiento jurídico de la crisis económica-financiera", Revista de Administración Pública, núm. 201, 2016, pp. 69-99.

${ }_{18}$ Francisco VELASCO, "Metodología comparativa para el Derecho administrativo", Revista Española de Derecho Administrativo, núm. 200, 2019, pp. 51-75. 
tuciones de Derecho privado, sino que también propone un concepto, funciones y método del Derecho comparado. Parten señalando que se trata de "una actividad intelectual en la que el derecho es el objeto y la comparación el proceso" ${ }^{19}$, para luego afirmar que "el Derecho comparado es la comparación de los diferentes sistemas legales del mundo" ${ }^{20}$. Su propuesta, como se reconoce expresamente, se entronca con aquella fundadora del derecho comparado moderno del Congreso Internacional de París de 1900, el cual apostaba a desarrollar o, más bien, descubrir, un "droit commun de l'humanitế. Esta tarea sería deseable, según se señalaba en aquella época, puesto que "si se establecieran principios de derecho generales claros y consistentes, se promovería el comercio internacional y mejorarían los niveles generales de vida, y si los juristas se asomaran más allá de sus fronteras nacionales, los intercambios internacionales se incrementarían" ${ }^{21}$.

A su juicio, se trata de una disciplina que puede presentarse como "una especie de ciencia pura" "22, que podría deslindarse conceptualmente de otras áreas del derecho, para luego afirmar que se trataría de "una école de la vérité que intensifica y enriquece la 'oferta de soluciones' (Zitelmann), pues proporciona al estudioso con talento crítico la oportunidad de hallar la 'mejor solución' a las situaciones de su tiempo y de su lugar" ${ }^{23}$. Si bien reconocen que "la meta primordial del derecho comparado es el conocimiento" ${ }^{24}$, le asignan un rol medular a la unificación del derecho ${ }^{25}$ como mecanismo para reducir los riesgos jurídicos de los negocios internacionales ${ }^{26}$. En efecto, plantean que si bien antes "los muy entusiastas se proponían unificar las leyes de todo el mundo, hoy es evidente que solo las necesidades específicas de los negocios internacionales pueden justificar la inmensa inversión de energía que se requiere para materializar cualquier proyecto de unificación" ${ }^{27}$.

De este modo, delimitada conceptualmente la disciplina, explicitados los fines que la justifican e informan, proponen un método para desarrollarla ${ }^{28}$. El quid de este último está en lo que denominan como "principio de funcionalidad", según el cual "lo único que puede compararse en el ámbito del Derecho son cosas que cumplan con una misma función" 29 , añadiendo luego que "los distintos sistemas jurídicos prescriben soluciones idénticas o muy similares, aun en los detalles, a los mismos problemas de la vida, pese a significativas diferencias en historia, estructura

19 Konrad ZWEIGERT y Hein KÖTZ, Introducción al Derecho Comparado, Oxford University Press México, México, 2002, p. 3.

20 Ibid.

21 Ibid., pp. 4-5.

22 Ibid., p. 8.

23 Ibid., p. 17.

24 Ibid., p. 18.

25 Ibid., p. 26.

26 Ibid., p. 27.

27 Ibid., p. 29.

28 Una variante particularmente influyente en: John REITZ, "How to Do Comparative Law", The American Journal of Comparative Law, vol. 46, 1998, pp. 617-636.

29 Konrad ZWEIGERT y Hein KÖTZ, op. cit., pp. 38-39. 
conceptual y estilo de operación" ${ }^{30}$. Ello lleva a otra formulación del principio de funcionalidad, que guiará la comparación antes de iniciarse y la controlará una vez finalizada: la denominada "praesumptio similitudinis" ${ }^{31}$. Dicha presunción operará, al comenzar una comparación, como "principio heurístico, pues nos indica a cuáles fuentes debemos recurrir en el Derecho y en la vida jurídica del sistema extranjero a efecto de observar similitudes y sustituciones" ${ }^{32}$. Luego, una vez finalizada, se constituye en un parámetro de revisión de los resultados: "el comparatista deberá darse por bien servido cuando sus investigaciones en los materiales relevantes lo lleven a la conclusión de que los sistemas comparados obtienen resultados idénticos o similares. Empero, si descubre que hay diferencias significativas o, de hecho, resultados opuestos, deberá tomar esto como una advertencia, por lo que habrá de comprobar si los términos en los que planteó la pregunta original eran funcionales y si, en efecto, ha extendido la red de sus investigaciones suficientemente lejos" ${ }^{33}$.

Como puede verse, la finalidad política reconocida expresamente en su propuesta coincide con el método que proponen, de tal manera que condiciona los resultados del trabajo comparativo. Así, si los negocios internacionales requieren uniformidad, el comparatista no solo puede aportarla mediante su trabajo intelectual, sino que estará metodológicamente condicionado para ello por esta "especie de ciencia pura".

\subsection{La crítica del comparatismo crítico}

La teoría antes expuesta ha sido objeto de diversas críticas, aquellas formuladas por el comparatismo crítico serán expuestas en esta sección. De entrada, puede destacarse que mientras Zweigert y Kötz enfocan su trabajo a lo que denominan derecho privado "más 'apolítico" " ${ }^{4}$, los autores críticos se centran sea en la discusión epistemológica del Derecho comparado, como Legrand, o en la comparación de Derechos constitucionales, como Frankenberg y Ponthoreau. Dado que la obra de estos tres autores es abundante y compleja, no se profundizará en todos sus aspectos, sino que solo se expondrán aquellos medulares.

Frankenberg, en un artículo hito en el comparatismo crítico ${ }^{35}$, propone otra forma de comparar. A su juicio, el comparatismo tradicional estaría dominado por un denominado "complejo de Cenicienta", según el cual los comparatistas, en el contexto de sus comunidades académicas, se sentirían aislados, subestimados, no adecuadamente apreciados por sus colegas y estudiantes ${ }^{36}$, lo cual los llevaría a despreocuparse

30 Ibid., p. 44.

31 Ibid., p. 45.

32 Ibid.

33 Ibid

34 Ibid

35 Günter FRANKENBERG, "Critical Comparisons: Re-Thinking Comparative Law”, Harvard International Law Journal, vol. 26, núm. 2, 1985, pp. 411-455.

36 Ibid., p. 419. 
de cuestiones teóricas y metodológicas, y les haría incurrir en lo que denomina "control cognitivo" ${ }^{37}$. Este último significaría elevar la propia concepción del derecho (legocentrismo) a categoría universal desde el cual estudiar lo otro (etnocentrismo). Respecto al funcionalismo, en especial, señala que incurrirían en una reificación del "principio de funcionalidad" sin considerar que no es más que un principio analítico que ordena el mundo real ${ }^{38}$. Todo lo anterior haría que el Derecho comparado refuerce construcciones justificatorias de determinadas realidades, marginalizando o, incluso, silenciando lo "primitivo", lo "no relevante", el otro ${ }^{39}$.

Ante ello, propone pasar desde el etnocentrismo a un autocriticismo y del legocentrismo a la crítica del Derecho. Lo primero conllevaría a reconocer que el comparatista está necesariamente cargado de conceptos, valores y visiones provenientes de su cultura jurídica local y su propia experiencia biográfica, en lo cual su propio lenguaje, culturalmente arraigado, juega un rol relevante; todo ello debe ser expuesto a una reexaminación autocrítica; en vez de buscar alguna pretendida postura neutral, objetiva o de desinteresado observador, debe mirarse como personalmente involucrado ${ }^{40}$. Por su parte, el legocentrismo debería dar paso a un comparatismo que sea capaz de enfrentarse a diversas expresiones del fenómeno jurídico, exponiendo sus deficiencias, contradicciones, componentes ideológicos y visiones que sobre él compiten ${ }^{41}$.

Estas críticas a los fundamentos de la doxa dominante entre los comparatistas resultan seminales en dos sentidos. Primero, para su propia obra, pues asienta los pilares con los cuales elabora su proyecto intelectual ${ }^{42}$. Segundo, pues sirve de puntapié inicial del comparatismo crítico. Por cierto, dada la relevancia de este artículo, constituye una referencia obligada sobre la teoría y el método del Derecho comparado.

Por su parte, la obra teórica de Legrand es bastante prolífica, destacando su breve pero aguda introducción al Derecho comparado, la cual puede servir tanto de primera aproximación a su trabajo, como de introducción a la disciplina ${ }^{43}$. Sin embargo, se considerarán especialmente sus dos últimos trabajos, puesto que

37 Ibid., p. 421.

38 Ibid., p. 440.

39 Ibid., p. 455.

40 Ibid., pp. 442-445.

41 Ibid., p. 448.

42 En efecto, así se expone en: Comparative Law as Critique, Edward Elgar Publishing, Cheltenham, 2016. Lo mismo en: Günter FRANKENBERG, Comparative Constitutional Studies. Between Magic and Deceit, Edward Elgar Publishing, Cheltenham, 2018. El curso hacia esos trabajos se va trazando con ciertos artículos fundamentales en su trabajo, tales como: Günter FRANKENBERG, "Stranger than Paradise: Identity \& Politics in Comparative Law”, Utah Law Review, núm. 2, 1997, pp. 259274. Ahí se explica cómo el trabajo académico de los comparatistas constituye también intervenciones políticas, y cómo el pensamiento dominante en el área podría convertirse en una versión posmoderna de imperialismo. Luego, las reflexiones metodológicas que serán incorporadas en el primero de los libros citados en esta nota, se exponen en: Günter FRANKENBERG, "How to Do Projects with Comparative Law. Notes of an Expedition to the Common Core", Global Jurist_Advances, vol. 6, núm. 2, 2006, pp. 1-30. Günter FRANKENBERG, "The Innocence of Method-Unveiled: Comparison as an Ethical and Political Act”, Journal of Comparative Law, núm. 9, 2014, pp. 222-158.

43 Pierre LEGRAND, Le droit comparé, Presses Universitaires de France, Paris, 1999. 
en ellos aclara, ilustra y, en cierto sentido, sistematiza su propuesta. En efecto, en su artículo "Negative Comparative Law" se propone delinear lo que denomina una "estrategia de gobernanza epistémica" que sea capaz de dotar de credibilidad la investigación sobre Derecho extranjero y legitimar los estudios de comparación jurídica ${ }^{44}$. Esta propuesta se presenta como alternativa crítica al funcionalismo o, como él lo denomina, "positivismo". Ocupa dicha denominación puesto que lo acusa de exportar la concepción propia del Derecho interno hacia la episteme con la cual intenta aproximarse a lo foráneo u otredad jurídica ${ }^{45}$. Como pude verse, comparte la tesis del legocentrismo planteada por Frankenberg, aunque luego se distanciará de sus propuestas ${ }^{46}$. Así, emprende una crítica demoledora a la ortodoxia disciplinar; la cual es negativa en un doble sentido: primero, porque niega doce tesis de las visiones tradicionales; y, segundo, porque lo hace desde un análisis dialéctico negativo, inspirado en Adorno ${ }^{47}$. Este autor ha sido catalogado como uno de los principales exponentes de una aproximación culturalista del derecho o diferencialista, denominada "Law as Culture" 48.

Según su primera tesis, el Derecho comparado no puede representar la foraneidad jurídica, todo intento de representación es siempre una representación, es decir, una nueva presentación de la realidad, que realiza una determinada subjetividad comparadora, cruzada por su propio "yo", y que, por cierto, no es la realidad misma, que permanecerá (resistirá) siempre como un "otro". Esto no significa, precisa, que el Derecho extranjero no sea accesible a ser pensado, sino que el razonamiento comparador no puede controlar, poseer o conocer la totalidad de la juridicidad foránea, puesto que el "yo" no puede ser, a la vez, el "otro" 49.

Luego, plantea que tampoco existe alguna pretendida "pureza" del Derecho, incluso, el propio Derecho puesto, teorizado por el positivismo, tiene una "positividad" mucho más profunda que lo que ella muestra. Esto es así, puesto que, desde un análisis etimológico de la palabra "texto" (del latín, "textor": tejedor), cada Derecho como texto es una red inagotable de trazos ("una fábrica de trazos") ${ }^{50}$ de configuraciones históricas, racionalidades políticas, lógicas sociales, postulados filosóficos, órdenes lingüísticos, prescripciones económicas, presupuestos epistémicos, etc., todo lo cual lo convierte en un "jurimorphs". De ese modo, la tarea del comparatista será escoger "hilos" tras los cuales ir "trazando" la positividad textual ${ }^{51}$. Sin embargo, siempre ha-

${ }^{44}$ Pierre LEGRAND, "Negative Comparative Law", Journal of Comparative Law, vol. 10, 2015, pp. $405-454$ (p. 405).

45 La mejor explicación de esta crítica en: Pierre LEGRAND, "Jameses at Play: A Tractation on the Comparison of Laws", The American Journal of Comparative Law, vol. 65, 2017, pp. 1-132.

46 Así, por ejemplo, en el análisis crítico que suscribe sobre el libro "Comparative Law as Critique" de Günter FRANKENBERG en: Simone GLANERT y Pierre LEGRAND, "Law, Comparatism, Epistemic Governance: There Is Critique and Critique", German Law Journal, vol. 18, núm. 3, 2017, pp. 701-719.

47 Pierre LEGRAND, "Negative Comparative Law", op. cit., pp. 409-411.

48 Marie-Claire PONTHOREAU, Droit(s) constitutionnel(s) comparé(s), op. cit., p. 121.

49 Pierre LEGRAND, "Negative Comparative Law", op. cit., p. 412.

50 Ibid., p. 420.

51 Ibid., pp. 421-422. 
brá un aspecto del texto que será inaccesible, inextricable, inexpresable, indescribible, secreto, tanto para el comparatista mismo como para su lector interno ${ }^{52}$, de manera que no queda más que resignarse a que no logrará desenredar todo ${ }^{53}$.

Estas dos primeras tesis permiten entender el camino que siguen las diez restantes: (1) no existe, entonces, objetividad en la comparación, (2) ni verdades en la interpretación, (3) ni método universal a emplear, (4) jamás podrá el comparatista genuinamente comprender, en sus propios términos, la otredad jurídica; (5) no hay la igualdad entre los Derechos, (6) ni son posibles los trasplantes jurídicos, (7) no existe algún pretendido Derecho universal, (8) no es posible afirmar que algún Derecho sea mejor que otro, (9) tampoco es posible traducir jurídicamente y (10) no existe globalización jurídica en los términos tradicionalmente entendidos ${ }^{54}$.

En lo que concierne a su tesis sobre el método no solo niega la posibilidad de uno de tipo universal ${ }^{55}$, que no sería más que el tautológico intento de acceder a algo predeterminado de antemano por sus concepciones implícitas ${ }^{56}$, sino que también plantea que el comparatista debe asumir una responsabilidad epistémica por su "tracing" del Derecho extranjero, respecto a ese espacio construido en el cual, no siendo Derecho propio ni foráneo, desarrolla sus propias traducciones, transacciones y disputas. De este modo, cada comparación consistirá en una nueva invención, que singulariza el Derecho extranjero, pero que permanece siempre como un evento singular ${ }^{57}$.

Por otro lado, Ponthoreau elabora su propuesta metodológica antes de las más recientes intervenciones de Legrand en el debate internacional, pero considera e incorpora su enfoque, al igual que la crítica de Frankenberg. A diferencia de los dos autores anteriores, se posiciona como una observadora de la discusión entre los que denomina enfoques "similaristas" y enfoques "diferencialistas". Su propuesta asimila la labor comparadora a la interpretación y argumentación, de manera que lo relevante sería explicitar las opciones metodológicas y políticas, y justificarlas de conformidad a los fines de la investigación que se pretenda. Lo anterior supone adquirir consciencia de la subjetividad que compara: asumir que siempre es un "yo" quien emprende esta tarea, con su propia historia y circunstancias. Así, se requiere previamente un proceso de deconstrucción jurídica y, después, uno de reconstrucción, puesto que la subjetividad nunca transita inalterada el proceso de aproximación al otro.

Respecto a la necesidad de justificación, precisa que el comparatista debe explicitar y justificar la elección de los casos como de la comparación misma que emprenda,

52 Ibid., p. 424.

53 Ibid., p. 422.

54 Esta tesis negativa se encuentra desarrollada previamente respecto a la supuesta convergencia de los derechos europeos en un artículo que gozó de particular difusión dado su carácter polémico: Pierre LEGRAND, "European Legal Systems Are Not Converging”, International and Comparative Law Quarterly, vol. 45, 1996, pp. 52-81.

55 Como el desarrollado en: Léontin-Jean CONSTANTINESCO, Traité de droit comparé, t. 2, La Méthode comparative, Librairie générale de droit et de jurisprudence, Paris, 1974.

56 Pierre LEGRAND, "Negative Comparative Law", op. cit., p. 435.

57 Ibid., p. 436. 
en especial, si adoptará un enfoque "similarista" (centrándose en la posibilidad de similitudes) o "diferencialista" (mediante una visión profunda del Derecho, que explore lo particular de lo estudiado), del mismo modo, deberá justificar sus criterios de comparación. Este ejercicio argumentativo le permitirá ser autocrítico, con su propia concepción del derecho, incluyendo sus preconcepciones y prejuicios; $\mathrm{y}$, a su vez, crítico con la concepción del derecho dominante en el medio en el cual se haya formado y con los discursos de los comparatistas. Del mismo modo, al evidenciar sus opciones y razones, podrá exponer su representación a la crítica de la comunidad nacional o internacional de comparatistas ${ }^{58}$.

Esta exposición permite sintetizar dos ideas importantes: primero, evidencia que toda comparación siempre es hecha por alguien, lo cual exige preguntarse iquién compara?; y, segundo, que existen preconcepciones sobre el fenómeno que se pretende estudiar que es necesario evidenciar para evaluarlas. Ambas consideraciones, a su vez, permiten justificar la pertinencia de preguntarse ¿cuáles son las preconcepciones (subjetivas y compartidas) respecto a la comparación de Derechos administrativos? Aquella pregunta exige detenerse críticamente tanto en el debate sobre la convergencia de Derechos, pues es considerado un supuesto de la comparabilidad de derechos administrativos, como en las visiones formalistas sobre aquellos, pues son las más difundidas.

\subsection{La especificidad de la comparación de derechos administrativos}

¿Existe una especificidad en la comparación de Derechos administrativos o se trata de una comparación como la de otras manifestaciones del fenómeno jurídico?, es decir, si lo que se pretende comparar impone consideraciones metodológicas particulares. Desde una perspectiva crítica es posible afirmar que el método solo puede aspirar a ser una construcción ad hoc, en un doble sentido: primero, para adecuarse a las particularidades de lo comparado; y, segundo, porque deberá, a continuación, elaborarse un método propio para la específica investigación que se pretenda, de modo que resulte funcional a los objetivos que se proponga. Aquello se justificaría tanto desde la filosofía de la ciencia ${ }^{59}$, como desde el Derecho comparado ${ }^{60}$.

En esta sección se explicará el carácter ad hoc en su primer sentido, lo cual exige hacerse cargo de dos cuestiones: desprenderse de la necesidad de funda la comparabi-

58 Marie-Claire PONTHOREAU, "Le droit comparé en question(s). Entre pragmatisme et outil épistémologique", Revue internationale de droit comparé, vol. 57, núm. 1, 2005, pp. 7-27. También en: Marie-Claire PONTHOREAU, Droit(s) constitutionnel(s) comparé(s), op. cit., 59-171.

59 En especial: Alan CHALMERS, ¿Qué es esa cosa llamada ciencia?, Siglo XXI, Madrid, 2015, pp. 152-163. También: Thomas KUHN, La estructura de las revoluciones científicas, Fondo de Cultura Económica, Ciudad de México, 4a ed., 2a reimp., 2017. Mauricio SUÁREZ, Filosofía de la ciencia, Historia y Práctica, Tecnos, Madrid, 2019.

${ }^{60}$ Pierre LEGRAND, "How to Compare Now", Legal Studies, vol. 16, 1996, pp. 232-242. Pierre LEGRAND, "Negative Comparative Law", op. cit. Mark VAN HOECKE, "Methodology of Comparative Legal Research", Law and Method, vol. 12, 2015, pp. 1-35. 
lidad de los Derechos administrativos en su supuesta convergencia y, luego, intentar construir una aproximación que no los reduzca a un puñado de textos de emanación estatal. Lo primero, puesto que la posibilidad e importancia de estas comparaciones no puede fundarse en la interesada lógica homogeneizante del principio de funcionalidad, sea explícito o implícito. Lo segundo, para que la comparación pueda dar cuenta lealmente de la alteridad jurídico-administrativa.

La globalización económica habría dado lugar a un fenómeno denominado "globalización jurídica", en el cual una de sus expresiones sería una cierta convergencia de Derechos administrativos a través del mundo ${ }^{61} \mathrm{y}$, muy especialmente, entre los países de la Unión Europea ${ }^{62}$.

Dicho fenómeno global se explicaría porque las diversas instituciones internacionales que van conduciendo el proceso de globalización económica, de conformidad a los grandes poderes reales transnacionales ${ }^{63}$, condicionan de facto la producción jurídica al interior de los Estados ${ }^{64}$. Si bien aquello pareciera haberse centrado en el Derecho vinculado de forma más inmediata a los negocios internacionales (lex mercatoria ${ }^{65}$ ), también tendría una expresión en el Derecho administrativo, es lo que Auby denomina una suerte de patrimonio común internacional de Derecho administrativo ${ }^{66}$.

En términos similares explica este fenómeno Chevallier, señalando que diversas instancias internacionales, especialmente el Banco Mundial y la OCDE, condicionan la producción jurídica intraestatal mediante una verdadera doctrina internacional de reforma administrativa: el New Public Management que apunta a reducir el peso del Estado y transformar sus métodos de gestión pública ${ }^{67}$. Este movimiento de difusión de nociones, técnicas y prácticas estaría dando lugar a una emergencia progresiva de un Derecho administrativo común, resultado de la hibridación de los sistemas existentes ${ }^{68}$; se trataría de un "fenómeno de hegemonía, que es difundido por mecanismos, explícitos o implícitos, de imposición” ${ }^{69}$.

Lo antes descrito ha servido de fundamento relevante para la comparatibilidad de los Derechos administrativos; en otros términos, dejaría de tener actualidad el

61 Véase supra nota núm. 5.

62 Véase supra nota núm. 6.

63 Jean-Philippe ROBÉ, "Les entreprises multinationales, vecteurs d'un nouveau constitutionnalisme”, Archives de philosophie du droit, núm. 56, 2013, pp. 337-361.

64 Oriol MIR, Globalización, Estado y Derecho. Las transformaciones recientes del Derecho Administrativo, Thomson Civitas, Madrid, 2004, p. 56.

65 Boaventura de SOUSA SANTOS, Sociología juridica crítica. Para un nuevo sentido común en el derecho, Trotta, Madrid, 2009, p. 94.

66 Jean-Bernard AUBY, op. cit., p. 242.

67 Jacques CHEVALLIER, L'État post-moderne, LGDJ, Paris, 2017, p. 90.

68 Ibid., p. 97.

69 Ibid. También en Günter FRANKENBERG, "Remarks on the Philosophy and Politics of Public Law”, Legal Studies, núm. 18, 1998, pp. 177-187 (p. 186-187). Manuel BALLBÉ, "El futuro del derecho administrativo en la globalización: entre la americanización y la europeización”, Revista de Administración Pública, núm. 174, pp. 215-276. 
antiguo lamento de los comparatistas de esta área (históricamente marginal) de carecer de un sustrato común entre los diversos países, a diferencia del Derecho privado construido desde el antiguo Derecho romano, el ius commune y el Derecho canónico. El factum de la convergencia de Derechos ha sido particularmente bien recibido por el comparatismo administrativo, tan así, que Janina Boughey afirmó que esta área sería la próxima frontera del Derecho comparado ${ }^{70}$, puesto que aquello permitiría "identificar un conjunto de tópicos de Derecho administrativo comunes que deberían atraer la atención de la comparación" ${ }^{71}$, con lo cual propone un programa tentativo de futuros desarrollos de comparación administrativa.

Como puede verse, pareciera que el razonamiento funcionalista condiciona el trabajo comparativo en esta área, exagerando el fenómeno de la convergencia, impulsándola y, de esa forma, naturalizando lo que resulta ser el interés de poderes existentes detrás de las instancias internacionales ${ }^{72}$. La ideología constituye la episteme y condiciona el resultado. Por cierto, esta constatación no pretende negar el factum de la convergencia, pues resulta evidente que, de leer diversos textos jurídicos a través del mundo, se pueden constatar ciertas tendencias comunes ${ }^{73}$. Por el contrario, lo que esta crítica propone es no asumir como obvio algo que no lo es y, a la vez, evidenciar lo que subyace a este quehacer académico. Es necesario mirar mucho más allá del simple hecho de su constatación.

Ponthoreau sugiere que, para un conocimiento profundo de este fenómeno jurídico, debería reformularse la tesis de la convergencia alrededor de una alternativa: "convergencia profunda y divergencias superficiales o convergencias superficiales y diferencias profundas" 74 , es decir, la convergencia no permite concluir nada de forma evidente u obvia. Dice mucho menos que lo que se le hace decir. Ante esas alternativas, si se sigue a Legrand, se puede afirmar que estamos más bien ante convergencia superficial (quizás meramente formal o discursiva y, sobre todo, interesada) pues bajo ella subyacen diferencias no solo profundas, sino también irreductibles.

En efecto, ningún Derecho existe en el aire, cada Derecho está localizado. Toda importación jurídica, cualquiera que sea, en cuanto es sintonizado con los intereses y preocupaciones locales, y operacionalizado, es transformado o reconfigurado ${ }^{75}$.

70 Janina BOUGHEY, "Administrative law: The next frontier for Comparative Law", op. cit., p. 55.

71 Ibid.

72 Pierre LEGRAND, "The Impossibility of Legal Transplants", Maastricht Journal of European and Comparative Law, vol. 4, núm. 2, 1997, pp. 111-124.

73 Francesca BIGNAMI, "Comparative administrative law", en Mauro BUSSANI y Ugo MATTEI (eds.), The Cambridge Companion to Comparative Law, Cambridge University Press, New York, 2012, pp. 145-170 (pp. 154-156).

74 Marie-Claire PONTHOREAU, "Trois interprétations de la globalisation juridique, Approche critique des mutations du droit public", op. cit., p. 25.

75 John BELL, "Researching Globalisation: Lessons from Judicial Citations", Cambridge Journal of International_and Comparative Law, vol. 3, 2014, pp. 961-982. También: John BELL, "The Argumentative Status of Foreign Legal Arguments", Utrecht Law Review, vol. 8, núm. 2, 2012, pp. 8-19. John BELL, "The Relevance of Foreign Examples to Legal Development", Duke Journal of Comparative \& International Law, vol. 21, 2011, pp. 431-460. 
Plantear que podría existir una comunicación no distorsionada, de manera que el Derecho extranjero podría traer consigo su foraneidad e implementarla de por sí en cualquier lugar es insostenible ${ }^{76}$. Por ello, "los vehículos de la estructura y hegemonía transnacional, independientemente de cuán poderosos sean, no pueden superar la contingencia radical del mundo y no pueden domesticar las significativas fuerzas centrífugas que continúan, especialmente, informando el life-in-the-law, aunque estos vectores se manifiesten fuera de los viejos modelos de soberanía nacional u otros nuevos como las corporaciones multinacionales, los acuerdos comerciales o la integración regional. El hecho es que no existe ningún lugar que pueda ser denominado no-local. [...] Cualquier manifestación de lo jurídico -incluso el más supuestamente 'global'- debe, en definitiva, ser localizado en el espacio, en algún lugar" 77 . Dicha reterritorialización se debe a que "lo global depende, en último término, de un local hacer que ocurra. En este proceso, cuando lo 'local' implementa lo 'global', lo transforma y lo fuerza a 'localizarse'. Hay un proceso de traducción/transformación operando" 78 . La noción que mejor describe aquello es la de "glocalización", puesto que "muestra útilmente el híbrido y complejo ensamblaje entre diseminación global y conocimientos locales. De forma crucial, este concepto implica diferenciación. [...] Insiste en el being-in-space del Derecho, en la morada del Derecho" 79 . Por ello, Frankenberg afirma que la pregunta interesante no es realmente si los trasplantes legales son posibles (en sentido estricto, no lo son), sino cómo ocurre la transferencia legal y qué sucede cuando acontece ${ }^{80}$.

Así, ante los discursos sobre la convergencia de derechos, fundados en el factum antes descrito, se evidencia toda la relevancia intelectual de los Derechos administrativos: son concretas manifestaciones de lo local; un aspecto propio de la condición de ser otro de cada cultura jurídica; un elemento crucial de su alteridad. En efecto, ellos permiten acceder a un aspecto fundamental de una realidad jurídica local oculto bajo los difundidos discursos sobre la convergencia de los textos constitucionales. Parafraseando a Ginsburg, se puede afirmar que en la actualidad el Derecho administrativo sería más (materialmente) ${ }^{81}$ constitucional que las constituciones ${ }^{82}$, fundante de la estatalidad real misma ${ }^{83}$, incluso, un componente estructural del Derecho ${ }^{84}$.

76 Pierre LEGRAND, “Negative Comparative Law”, op. cit., p. 439. También: Joseba GABILONDO, Globalizaciones. La nueva Edad Media y el retorno de la diferencia, Editorial Siglo XXI, Madrid, 2019. Boaventura DE SOUSA SANTOS, op. cit., p. 309.

77 Pierre LEGRAND, "Negative Comparative Law", op. cit., p. 445.

78 Ibid., p. 446.

79 Ibid.

80 Günter FRANKENBERG, Comparative Constitutional Studies, op. cit., p. 155.

81 Marco GOLDONI y Michael WILKINSON, “The Material Constitution”, The Modern Law Review, vol. 81, núm. 4, 2018, pp. 567-597.

82 Tom GINSBURG, "Written constitutions and the administrative state: on the constitutional character of administrative law" en Susan ROSE-ACKERMAN y Peter LUNDSETH, Comparative Administrative Law, Edward Elgar Publishing, Cheltenham, 2010, pp. 117-127 (p., 117).

83 Jacques CAILLOSSE, L'État du droit administratif, LGDJ, op. cit., pp. 31-32.

84 Boaventura DE SOUSA SANTOS, op. cit., pp. 57-62. 
Ponthoreau explica ese fenómeno de lo global, el denominado constitucionalismo global, señalando que existe una base empírica innegable, consistente en la difusión mundial de la forma constitucional escrita, en la cual se consagran catálogos de derechos, con un mínimo de inspiración liberal, junto a las bases de una democracia pluralista y el estado de derecho ${ }^{85}$. Sin embargo, aquello poco dice sobre lo que se pretenda estudiar. Nada descarta, y seguramente no será difícil encontrar casos en ese sentido, que esta forma constitucional sea utilizada por ciertas élites gobernantes a efectos de intentar legitimarse ante la comunidad internacional, permitiéndose crear una retórica que oculte su realidad. Por su parte, ese factum constitucional, es construido por, y permite construir, discursos doctrinales homogeneizantes que ocultan, niegan o simplemente desplazan otras posibilidades distintas al liberalismo globalmente hegemónico ${ }^{86}$. Es decir, utilizando una metáfora, se impone el uso de determinados lentes que impiden ver todo aquello que no se quiere que sea visto. Por lo tanto, se puede afirmar que un elemento fundamental para aproximarse a una cultura jurídica estaría, precisamente, en el derecho administrativo, pues explicaría la realidad de las relaciones del poder político institucionalizado de cada caso a estudiar, sin caer en la trampa de textos constitucionales homogeneizados ${ }^{87}$.

Así, es posible invertir la idea de que el Derecho administrativo concreta el Derecho constitucional ${ }^{88}$, puesto que, en cierto sentido, ha devenido en el propio Derecho constitucional, puesto que este último, en sus expresiones doctrinales y textuales podría ocultar la realidad o materialidad constitucional. Es decir, una parte fundamental de aquello constitutivo de la alteridad jurídica misma será el Derecho administrativo, de manera que su estudio deja de ser algo secundario o pintoresco y deviene en una tarea crucial del comparatismo.

Sin embargo, lo anterior también implica una pregunta tan desafiante como ineludible: ¿qué entender por Derecho administrativo?, vale decir, ¿qué es aquello que se va a comparar?, la respuesta no es obvia. En efecto, no puede limitarse a una estrecha e ingenua aproximación a determinados textos oficiales que, precisamente, expresan o permiten elaborar los discursos de la convergencia y ocultar la real operación que acontece en el espacio local o doméstico.

85 Marie-Claire PONTHOREAU, 2018, “'Global Constitutionalism'. Un discours doctrinal homogénéisant, L’apport du comparatisme critique”, op. cit., pp. 110-113.

${ }_{86}$ Esta misma sospecha en Thomas FLEINER, "Comparative Constitutional and Administrative Law”, Tulane Law Review, vol. 75, 2001, pp. 929-940 (p. 939).

${ }^{87}$ Tom GINSBURG, op. cit. Janina BOUGHEY, op. cit., pp. 70-73. Jacques ZILLER, Administrations comparées : les systèmes politico-administratifs de l'Europe des Douze, Montchrestien, Paris, 1993, pp. 12-13. Sabino CASSESE, La construction du droit administratif. France et Royaume-Uni, Montchrestien, Paris, 2000, p. 11. Marie-Claire PONTHOREAU, "'Global Constitutionalism'. Un discours doctrinal homogénéisant, L’apport du comparatisme critique”, op. cit., pp. 130-131.

88 Expresión de Friz Werner, citada, explicada y problematizada en Luis ARROYO, "Derecho Administrativo y Constitución Española”, Revista de Administración Pública, núm. 209, 2019, pp. 145174 (p. 148). 
Explorar intelectualmente estas materias exige plantearse las preguntas fundamentales de la disciplina. Tal como el Derecho comparado debe cuestionarse qué es el Derecho y trabajar con alguna respuesta más o menos tentativa que le permita delimitar el objeto de su estudio; la comparación de Derechos administrativos exige, a su vez, preguntarse qué se entiende por aquella específica expresión del fenómeno jurídico. Ninguna de las respuestas es obvia, pero sí resulta evidente, por lo previamente expuesto, que definiciones puramente formales no otorgan respuestas satisfactorias ${ }^{89}$. En efecto, aquello se debe, principalmente, a dos motivos: primero, a la contingencia histórica del propio Derecho positivo que impide considerarlo como algo a priori o producto del puro intelecto sin interacción con la realidad social que lo genera; como, a su vez, por el hecho que las concepciones formalistas son un producto histórico que se circunscribe en una específica expresión del fenómeno jurídico, propio de la modernidad occidental y el (su) Estado moderno ${ }^{90}$. En otros términos, proyectar las concepciones formales del Derecho (logocentrismo/europeocentrismo), adquiridas en la formación jurídica hegemónica en los medios continentales, como lentes desde los cuales observar el derecho en el mundo, se constituirá en un obstáculo para el genuino intento de comprensión del otro.

Lo anterior exige que la comparación de Derechos administrativos sea capaz de construir concepciones materiales funcionales a los objetivos de la comparación, como de una investigación en particular ${ }^{91}$. De este modo, si se trata de realizar estudios comparados de tradiciones jurídicas históricamente más vinculadas, sería posible elaborar un concepto más restringido de Derecho administrativo, mientras que si se trata de comparaciones más heterogéneas probablemente se requerirá uno más amplio. Así, por ejemplo, casos más próximos como serían Francia, España e Italia podrían contar con un concepto relativamente restringido y con un mayor grado de abstracción ${ }^{92}$, mientras que comparar Ruanda, Vietnam, Hungría y Bolivia requeriría un concepto más amplio.

Lo anterior, por cierto, no excluye la pertinencia de explorar un concepto operatorio o funcional a cualquier comparación en general, lo cual exigiría reconocer la contingencia histórica de la idea de Derecho público ${ }^{93}$, pues tanto el término como su contenido son expresiones del desarrollo histórico del Derecho occidental ${ }^{94}$ y su

89 Marie-Claire PONTHOREAU, Droit(s) constitutionnel(s) comparé(s), Economica, op. cit., pp. 55, 97-100.

90 Alejandro NIETO, Crítica de la Razón Jurídica, Editorial Trotta, Madrid, 2007. Michel MIAILLE, op. cit., p. 347, 371 y p. 376.

${ }^{91}$ Así lo hacen, de forma ad hoc, Janina BOUGHEY, op. cit., p. 56. Francesca BIGNAMI, "From expert administration to accountability network: a new paradigm for comparative administrative law", The American Journal of Comparative Law, vol. 59, 2011, pp. 859-907.

92 Oriol MIR, "El concepto de derecho administrativo desde una perspectiva lingüística y constitucional”, Revista de Administración Pública, núm. 162, 2003, pp. 47-87. Luciano PAREJO, El Concepto de Derecho Administrativo, Editorial Jurídica Venezolana, Caracas, 1984.

93 Dieter GRIMM, Sobre la identidad del derecho público, Centro de Estudios Políticos y Constitucionales, Madrid, 2015, p. 13.

94 Didier BLANC, "Les naissances du droit public, Pour une généalogie en forme de trilogie", Revue du Droit Public et de la Science Politique en France et à l'Etranger, núm. 6, 2017, pp. 1561-1579. 
delimitación ha dependido de cada experiencia histórica particular ${ }^{95}$. La plausibilidad del resultado estará en su capacidad explicativa de lo que se pretende estudiar. Es decir, sería posible construir un meta-concepto comparativo ${ }^{96}$ que remita a algo con cierto sentido. Si bien emprender dicha tarea requiere una investigación propia, sería posible adelantar que de pagarse el costo de excluir la comparación diacrónica de fenómenos no-modernos, se podría ganar en precisión de un concepto que, haciéndose cargo de la "mundialización del Estado" 97 , sea capaz de comparar sus diversas expresiones locales.

Finalmente, para ejemplificar lo previamente desarrollado, considérese el caso de los Derechos latinoamericanos, ilustradores no solo por su heterogeneidad, sino, especialmente, por encontrarse en los márgenes de la globalización. En el contexto de la clásica clasificación de familias jurídicas de René David ${ }^{98}$, se les consideró un simple apéndice del Derecho occidental, sea en su vertiente continental (mayoritariamente) o anglosajona. Serían, en términos de Zweigert y Kötz, "sistemas legales afiliados" por imitar "sistemas originales", y, por ello, "carecerán de esa mezcla de originalidad y equilibrio para resolver problemas que caracteriza al sistema legal significativo" 99.

Sin embargo, en este caso, el funcionalismo evidencia graves problemas, por resultar ciego a lo que pretende explicar. En efecto, donde vería convergencia, en realidad, no hay más que una retórica que utiliza las categorías jurídicas importadas desde los lugares que se perciben como centros de producción intelectual ${ }^{100}$. Bajo ello se desenvuelven realidades diversas y lógicas complejas ${ }^{101}$ que el comparatista requiere comprender para acercarse lealmente a esa otredad, las cuales dotan a los Derechos latinoamericanos de sus respectivas particularidades, cuyas interacciones permitirían, incluso, afirmar que se trata de un espacio jurídico con identidad propia ${ }^{102}$. Esto ha llevado a algunas de las más recientes formulaciones de clasificaciones macrocomparativas a considerarla una tradición distinta ${ }^{103}$, o, incluso, como un espacio de posibilidades jurídicas alternativas ${ }^{104}$.

${ }^{95}$ Francisco VELASCO, Derecho público más Derecho privado, Marcial Pons, Madrid, 2014, pp. 49-75.

96 Michel TROPER, La théorie du droit, le droit, l'État, Presses Universitaires de France, Paris, 2001, pp. 51-66. Michel TROPER, "L'histoire du droit, le droit comparé et la théorie générale du droit”, Revue internationale de droit comparé, vol. 67, núm. 2, 2015, pp. 331-340.

${ }^{97}$ Jacques CHEVALLIER, Science administrative, Presses Universitaires de France, Paris, $6^{\mathrm{a}}$ ed., 2019, p. 194.

98 Thierry RAMBAUD, op. cit., pp. 55-56.

99 Konrad ZWEIGERT y Hein KÖTZ, op. cit., p. 46.

100 César RODRÍGUEZ, El derecho en América Latina, Un mapa para el pensamiento jurídico del siglo XXI, Siglo XXI editores, Buenos Aires, 2011, p. 15.

101 Diego LÓPEZ-MEDINA, "The Latin American and Caribbean legal traditions, Repositioning Latin America and the Caribbean on the contemporary maps of comparative law", en Mauro BUSSANI y Ugo MATTEI (eds.), The Cambridge Companion to Comparative Law, Cambridge University Press, New York, 2012, pp. 344-367.

102 Ibid.

103 Ugo MATTEI, "Three Patterns of Law: Taxonomy and Change in the World's Legal Systems", The American Journal of Comparative Law, vol. 45, 1997, pp. 5-44.

104 Marie-Claire PONTHOREAU, “'Global Constitutionalism'. Un discours doctrinal homogénéisant, L’apport du comparatisme critique”, op. cit., pp. 131-133. 
Dicha ceguera no solo ha tenido proyección en el quehacer académico, sino que también ha repercutido negativamente en las diferentes realidades locales ${ }^{105}$, en una especie de alienación jurídica: se habla sobre un Derecho que existe en los discursos doctrinales, en los textos de sentencias, en los manuales, más o menos sistematizado según las lógicas positivistas hegemónicas, pero que ocultan la juridicidad profunda que se requiere comprender para realizar trabajos comparativos con plausibilidad explicativa ${ }^{106}$.

Así, habiendo problematizado la especificidad de la comparación de Derechos administrativos, se está en condiciones de avanzar en la construcción de herramientas que permitan desarrollar una investigación concreta.

\section{HERRAMIENTAS METODOLÓGICAS PARA COMPARAR DERECHOS ADMINISTRATIVOS}

Como se explicó previamente, cada investigación deberá elaborar su propio "método" (ad-hoc) adecuado a los fines que pretenda ${ }^{107}$, por ello, esta propuesta se presenta como una de tipo abierta, flexible y provisional. Se trata de un conjunto de "herramientas metodológicas" a elección de quien pretenda acercarse a Derechos administrativos para compararlos. Aquellas deben permitir elaborar un discurso razonado, razonable y fundado ${ }^{108}$, posible de ser sometido a crítica ${ }^{109}$, en el cual se expliciten las diversas opciones que se vayan adoptando. En suma, se trata de un discurso argumentativo ${ }^{110}$ sobre interpretaciones y, por lo tanto, aunque no da a conocer las cosas por sí mismas, sí lo que el comparatista ha adquirido, en forma de una exposición idónea ${ }^{111}$. Dichas herramientas permiten elaborar un espacio de comparación propio de cada comparatista, el cual opera de forma singular en cada una de sus investigaciones.

Para estructurar el carácter $a d$ hoc de esta propuesta, se procederá en tres momentos que coinciden con las preguntas propias de la tarea de comparar derechos. Efectivamente, dicha labor usualmente ha conllevado tres interrogantes ${ }^{112}$ : ¿qué comparar? ¿cómo hacerlo? y ¿para qué? Sin embargo, se debe añadir una cuarta: ¿quién com-

105 Jorge ESQUIROL, "The Failed Law of Latin America", The American Journal of Comparative Law, vol. 56, 2008, pp. 75-124.

106 Sherally MUNSHI, "Comparative Law and Decolonizing Critique", The American Journal of Comparative Law, vol. 65, 2017, pp. 207-236.

107 Jaakko HUSA, op. cit., p. 1115.

108 Ponthoreau señala que debe tratarse de "un discurso argumentativo razonable". Marie-Claire PONTHOREAU, "Droits étrangers et droit comparé: des champs scientifiques autonomes?", Revue internationale de droit comparé, vol. 67, núm. 2, 2015, pp. 299-315 (p. 311).

109 Ibid., p. 309.

110 Marie-Claire PONTHOREAU, "Le droit comparé en question(s). Entre pragmatisme et outil épistémologique”, op. cit., p. 19.

111 Pierre LEGRAND, "Comparer", op. cit., p. 286.

112 Etienne PICARD, op. cit., p. 320. 
para? Mientras la primera pregunta se intentó responder previamente, se pasará a la segunda de ellas (métodos), lo cual, a su vez, dependerá de la tercera respuesta (fines) -el carácter ad hoc del método, en su segundo sentido-. Todo lo anterior, a su vez, estará cruzado por la última respuesta (subjetividad).

\subsection{El factor biográfico: de la deconstrucción a la reconstrucción de sí}

Toda comparación está cruzada por la subjetividad de quien la emprende ${ }^{113}$, tanto por los datos personales de su biografía, como por su formación; en especial, por el medio en el cual se educó y se desenvuelve. Aquello requerirá un reexamen autocrítico, para tomar distancia y descentrarse (Frankenberg), un proceso de deconstrucción y reconstrucción, de introspección sobre sí mismo (Ponthoreau), un retorno sobre sí (Legrand). Como explica Ponthoreau, "no se trata estrictamente de una destrucción de los conocimientos adquiridos, sino de un reexamen minucioso de aquello que ha sido aprendido durante la formación jurídica a fin de reconstruirlo, tomando conciencia que no se razona necesariamente de la misma manera" ${ }^{114}$.

Para llevar adelante un proceso de este tipo, resultará necesario cuestionarse todo lo que sea posible cuestionar, no asumir como obvio nada. Así, al menos resultaría necesario reflexionar sobre los sesgos cognitivos ${ }^{115}$, la cultura en la cual se ha formado y, en ella, la específica cultura jurídica, para, posteriormente, cuestionar sus supuestos y categorías asentadas. Como explica Legrand, "los juristas son ellos mismos productos culturales situados, de una sociedad dada que operan en una coyuntura espaciotemporal bien precisa" 116; puesto que el Derecho "se distingue por su participación en una tradición que constituye su horizonte, es decir, una estructura preindividual metastable interiorizada, estructurada y estructurante (en el sentido que ella deviene una disposición mental, una disposición profunda que orienta la relación a sí mismo). A partir de lo cual, cada individuo dentro del Derecho está marcado por una socialización que hace que no sea completamente dueño de su pensamiento y de sus acciones" 117 . "Es la tradición -nuestra comunidad histórica, nuestra morada (nuestro "palacio ancestral", para hablar como Benjamin) la que constituye el trasfondo y, entonces, la condición de posibilidad de conocimiento del jurista, de sus juicios de

113 Pierre LEGRAND, “Comparer”, op. cit., p. 309.

114 Marie-Claire PONTHOREAU, "Le droit comparé en question(s). Entre pragmatisme et outil épistémologique", op. cit., 12.

115 Acá será de utilidad aproximarse a la teoría de los sesgos cognitivos: Amos TVERSKY y Daniel KAHNEMAN, "Judgment under Uncertainty: Heuristics and Biases", Science, New Series, vol. 185, núm. 4157, 1974, pp. 1124-1131. Arturo MUNOZ, "La influencia de los sesgos cognitivos en las decisiones jurisdiccionales: el factor humano. Una aproximación", INDRET Revista para el análisis del derecho, núm. 2, 2011, pp. 1-39.

116 Pierre LEGRAND, "Comparer", op. cit., p. 282.

117 Pierre LEGRAND, "Sur l'analyse différentielle des juriscultures", Revue internationale de droit comparé, vol. 51, núm. 4, 1999, pp. 1053-1071 (p. 1055). 
valor y de sus opiniones críticas"118; por cierto, no se trata de "colocar la autoridad de la tradición por sobre la razón, sino de recordar que la razón se inscribe siempre dentro de un marco histórico y comunicacional, y rechazar las aberraciones de una razón que se cree soberana en relación al tiempo" ${ }^{119}$.

Una consecuencia de esta constatación debiera ser el cuestionamiento de los supuestos epistemológicos e ideológicos hegemónicos en la tradición ${ }^{120}$ que se formó el jurista y, en particular, en su aproximación al Derecho administrativo también deberá realizar un cuestionamiento similar ${ }^{121}$, en especial, de los discursos doctrinales dominantes: ¿cómo operan?, ¿cuáles son sus supuestos?, ¿siempre ha sido así?, ¿debe necesariamente ser así?, etc. De este modo, sus teorías sobre qué es el Derecho, qué es el poder, qué es el poder político, el Estado, el sistema político, la dominación, la burocracia, etc., no pueden darse por obvias y deben ser cuestionadas. Así, podrá constatarse cómo, en los medios dominados por paradigmas formalistas o idealistas, no sería extraño constatar que los administrativistas no discuten realmente sobre sus genuinos desacuerdos, $i$. e. sus contrapuestas visiones sobre el mundo que proyectan en sus trabajos "dogmáticos", mientras participan de la conflictividad social constitutiva de la estatalidad misma.

De este autoanálisis, debiera surgir una reconstrucción explicitada. Obviamente, no se trata de realizar una teorización de cada una de dichas inabarcables problemáticas, sino simplemente cuestionarse, revisar otras aproximaciones y explicitar sintéticamente el resultado, sea mediante una simple referencia, sea mediante conceptos funcionales a su trabajo u otros mucho más ambiciosos intelectualmente. Por otro lado, también resultaría de utilidad explicitar los intereses personales como los condicionantes materiales de la investigación, sea como simple acto de honestidad intelectual para su medio, sea para explicar eventuales proyecciones en su trabajo.

En síntesis, el Derecho comparado, en tanto crítica, además de cumplir una función subversiva de los discursos dominantes sobre el Derecho, cumpliría también una de tipo autosubversión-permanente, pues luego de imponer preguntas complejas, permite ampliar las perspectivas, enriquecer los propios discursos jurídicos y luchar contra las costumbres de pensamiento anquilosantes ${ }^{122}$.

\section{Ibid.}

119 Ibid., p. 1056.

120 Mark VAN HOECKE y Mark WARRINGTON, "Legal Cultures, Legal Paradigms and Legal Doctrine: Towards a New Model for Comparative Law”, International and Comparative Law Quarterly. vol. 47, 1998, pp. 495-536. Aplicando esta categoría al ámbito europeo en: Mark VAN HOECKE y François OST, "Legal doctrine in crisis: towards a European legal science”, Legal Studies, vol. 18, núm. 2, 1998, pp. 197-215. Emmanuel JEULAND, op. cit., pp. 382 y 386.

121 Régis PONSARD, "Pour une épistémologie de la science du droit administratif?", en VVAA, Les Méthodes en droit administratif, DALLOZ, Paris, 2018, pp. 99-132. Sabino CASSESE, Culture et politique du droit administratif, DALLOZ, Paris, 2008. La explicación sobre cómo opera la ideología administrativa en: Jacques CHEVALLIER, Science administrative, op. cit., pp. 543-545.

122 Horatia MUIR-WATT, "La fonction subversive du droit comparé", Revue internationale de droit comparé, vol. 52, núm. 3, 2000, pp. 503-527 (p. 506). 


\subsection{Herramientas para la construcción ad hoc de un espacio de comparación}

La autosubversión explicada anteriormente dará paso a la construcción de un espacio de comparación propio del comparatista, desde el cual trabajar la investigación que emprenda sobre Derechos administrativos. Para ello, se proponen cinco herramientas, las cuales deberían ser evaluadas con vistas a los fines concretos del trabajo de comparación que se desarrolle.

\subsubsection{Herramienta uno: deconstrucción y reconstrucción contextualizada del Derecho extranjero}

El Derecho extranjero es el supuesto del Derecho comparado; estos dos saberes, aunque distintos, se relacionan: comparar supone aproximarse al otro-jurídico, pero en los propios términos de su alteridad. Por ello, su comprensión no corresponde solamente a una acumulación de datos ${ }^{123}$, ni a un lineal período de tiempo "observando" y luego otro "escribiendo", se trata, más bien, de un ir y venir reflexivo tanto del Derecho positivo (las relaciones entre los textos jurídicos), luego de aquel en su específica cultura jurídica y, aquella, en la cultura/sociedad en la cual se inserta. Por cierto, esta contextualización no es una cuestión del todo o nada, sino de grado, y aquel deberá ser adecuado (ad hoc) a los objetivos de la investigación ${ }^{124}$. Se trata de construir una visión lo más leal posible del Derecho administrativo foráneo.

En este proceso, el principal riesgo es que el jurista deforme aquella realidad en la cual no se encuentra ${ }^{125}$, por ello se aconseja la "inmersión" ${ }^{26}$, puesto que la cultura de una sociedad (y que condiciona su cultura jurídica y Derecho positivo) no se limita a manifestaciones textuales, sino que es algo que "se vive".

Finalmente, junto con mirar con recelo las clasificaciones de familias de Derechos, por no adecuarse a las particularidades del Derecho público ${ }^{127}$, será crucial el estudio del respectivo sistema político en el cual se encuentra el caso a estudiar. Ziller plantea que para comprender una administración resulta necesario conocer el funcionamiento de su sistema político, tanto porque es difícil delimitarlo del sistema administrativo, como porque aquel produce las políticas públicas que este aplica ${ }^{128}$.

123 Marie-Claire PONTHOREAU, Droit(s) constitutionnel(s) comparé(s), op. cit., p. 305.

124 Ibid., p. 307.

125 Ibid., p. 306.

126 Marie-Claire PONTHOREAU, “'Global Constitutionalism'. Un discours doctrinal homogénéisant, L’apport du comparatisme critique”, op. cit., p. 127.

127 Marie-Claire PONTHOREAU, Droit(s) constitutionnel(s) comparé(s), op. cit., p. 43.

128 Jacques ZILLER, op. cit., pp. 12-13. 


\subsubsection{Herramienta dos: justificación de la selección de casos}

Para construir un discurso razonable y con utilidad explicativa, aquel debe ser justificado. Por ello no puede evadirse la pregunta ¿por qué estos casos? Ponthoreau, desde el trabajo de Hirschl ${ }^{129}$, plantea cuatro posibles razones para seleccionar casos, y que permitirían justificar preliminarmente su elección, de manera que no se trate de simple arbitrariedad, imaginación o intuición ${ }^{130}$. Así, podrían escogerse los que pareciesen ser (i) los casos más similares posibles; (ii) los más diferentes posibles; o bien, (iii) escoger un caso del cual examinar similitudes y diferencias para ofrecer una comprensión compleja de su realidad jurídica; o (iv) seleccionar los casos singulares ${ }^{131}$. Por cierto, se tratará de una aproximación preliminar fundada en las fuentes preliminares que justificaron una investigación, puesto que el abanico de lecturas y fuentes siempre podrá reconfigurar el trabajo ${ }^{132}$.

De este modo, por ejemplo, se podría justificar un estudio sobre las relaciones entre el Derecho administrativo de Francia y el de España, pues es un lugar común afirmar sus similitudes fundadas en la decisiva influencia del primero sobre el segundo. Sin embargo, aquello solo se trata de un punto de partida cuyo objetivo sería precisamente cuestionarlo, tal como lo hace Neyrat ${ }^{133}$.

\subsubsection{Herramienta tres: considerar la trampa del lenguaje}

Si bien el problema lingüístico (la trampa del lenguaje) ${ }^{134}$ es parte de la contextualización, requiere tratarse como tópico especial, por uno de sus problemas medulares: la traducción. Con todo, este asunto es más amplio que aquella, puesto que incluso en casos que comparten un mismo idioma se generan problemas de comunicabilidad de categorías jurídicas. El espacio latinoamericano sería un buen ejemplo, como se explicó.

Respecto a la traducción, cuando se pretende estudiar un Derecho extranjero que utiliza una lengua distinta a la del comparatista, "resulta necesario al comparatista iniciar su investigación armado de una teoría de la traducción la cual, por sí sola, le dará la ocasión de resolver, aunque imperfectamente, las trampas que le tiende la imbricación del Derecho y la lengua" ${ }^{135}$. De manera que una aproximación a las

129 Ran HIRSCHL, "The Question of Case Selection in Comparative Constitutional Law", The American Journal of Comparative Law, vol. 53, 2005, pp. 125-155.

${ }_{130}$ Marie-Claire PONTHOREAU, "Droits étrangers et droit comparé: des champs scientifiques autonomes?", op. cit., p. 310.

131 Marie-Claire PONTHOREAU, Droit(s) constitutionnel(s) comparé(s), op. cit., pp. 78-82.

132 Ibid., p. 81.

133 Anna NEYRAT, Le rapport du droit administratif national aux droits administratifs étrangers. Les cas de la France et de l'Espagne, L'Harmattan, Paris, 2019.

134 Marie-Claire PONTHOREAU, Droit(s) constitutionnel(s) comparé(s), op. cit., pp. 90-94.

135 Pierre LEGRAND, "Comparer", op. cit., p. 311. 
teorías de la traducción resultará ineludible, para estos efectos resulta útil la sintética exposición de De la Sierra ${ }^{136}$.

\subsubsection{Herramienta cuatro: el tracing de textos}

Si bien la textualidad no será la única fuente a considerar, la positividad textual es una forma relevante para aproximarse al fenómeno jurídico e, incluso, desde ella es posible desarrollar toda una contextualización cultural. En efecto, la positividad de los textos jurídicos es mucho más rica que lo que pareciera verse a primera vista, como explica Legrand, "hay estratos de un Derecho que su positividad de superficie disimula pero que resultan esenciales para una rica comprensión de aquella positividad misma" 137 . "Para realmente conocer el estado del Derecho en un contexto dado, es, entonces, imperativo analizar sus cimientos culturales" ${ }^{138}$, se trata de "los vínculos entre el Derecho y la lengua, entre el Derecho y el orden social, económico o político, entre el Derecho y la historia, entre el Derecho y las tradiciones filosóficas y morales que son ancladas en un territorio dado" ${ }^{139}$. Esos caminos pueden ser explorados a través del texto, mediante el "tracing" que propone Legrand. Aquello consiste en un proceso de "deshebrar" el texto tal como si fuese un tejido: cada nudo llevará a otro, pues cada palabra es toda una manifestación histórico-cultural, tanto como la textualidad misma. Aunque ese proceso resultará siempre subjetivamente inabarcable (desde esta perspectiva, los textos no tendrían principio ni fin, ni una estructura necesaria en sí), no obstará a que dicha experiencia, concreta e irrepetible, permita elaborar un discurso que represente ese viaje por los hilos del texto.

Así, por ejemplo, que el famoso arrêt Blanco de 1873 incluya la expresión "le service public" y que, a ese texto, respecto a esa expresión, se le haya hecho decir un discurso teórico-doctrinal construido décadas después, dice mucho más sobre la sociedad francesa y cómo su derecho administrativo ha operado en el siglo xx, que sobre el particular problema "dogmático" del régimen jurídico de la responsabilidad del Estado o el verdadero origen del Derecho administrativo francés ${ }^{140}$.

Lo anterior tiene dos consecuencias, primero, el comparatista, siguiendo el "tracing", va tras la diferencia, lo que hace al otro su calidad de tal. Segundo, toda comparación será necesariamente interdisciplinaria, puesto que exigirá una pluralidad de aproximaciones, "como un proceso de dominio de préstamos recíprocos, entre las diversas sciences de l'homme, de conceptos, de problemáticas y de métodos para

136 Susana DE LA SIERRA, Una metodología para el Derecho Comparado europeo, pp. 106-111.

137 Pierre LEGRAND, “Comparer”, op. cit., p. 291.

138 Ibid., p. 281.

139 Ibid., p. 282.

140 Thomas PERROUD, Jacques CAILLOSSE, Jacques CHEVALLIER y Danièle LOCHAK (dirs.), Les grandes arrêts politiques de la jurisprudence administrative, LGDJ, Paris, 2019, p. 40-62. Charles BOSVIEUX-ONYEKWLU, "Revenir sur une légende en sociologie: l'arrêt Blanco et le mythe de la 'naissance' du droit administratif français”, Droit et Société, núm. 101, 2019, pp. 159-178. 
lecturas renovadas de la realidad social" ${ }^{141}$."La práctica de la comparación se hace indisciplinada, es decir, interdisciplinaria -ella interviene entre disciplinas diversas- en cuanto comprende que todo pensamiento disciplinado amenaza de oscurecer en un dogmatismo hipostasiado" ${ }^{142}$.

Con todo, también podría avanzarse hacia una transdisciplinariedad como propone Husa, en la cual personas con diferentes competencias y conocimientos conformen grupos de investigación, integrados por abogados, historiadores, sociólogos, cientistas políticos, lingüistas y antropólogos. Esto aseguraría, según precisa el mismo autor, la utilización de diversos métodos y metodologías. De este modo se evitan aproximaciones marcadas por el formalismo de los abogados, sin incurrir en el imposible que una sola persona se forme en todas dichas disciplinas ${ }^{143}$.

\subsubsection{Herramienta cinco: la conceptualización y la comparación conceptual}

Parte importante de la razonabilidad del espacio de comparación que se construya en una investigación estará dado por una adecuada utilización de la conceptualización. Su precisión y justificación sería crucial. En efecto, si el lenguaje jurídico, incluyendo aquel empleado en los discursos doctrinales del Derecho comparado, no es más que una variante del lenguaje natural, entonces será su precisión la que podrá dotarlo de rigurosidad y mejor comunicabilidad ${ }^{144}$.

En esta materia, resultan imprescindibles los trabajos de Silvia Díez ${ }^{145}$, Oliver Brand $^{146} y$, en especial, de Reinhart Koselleck ${ }^{147}$. La primera, puesto que problematiza la conceptualización como asunto metodológico en el Derecho público; el segundo porque estudia la conceptualización como herramienta del comparatista en el contexto de la discusión teórico-metodológica reciente; el tercero, como fundador de una corriente, teoriza el estudio histórico de los conceptos, particularmente útil para comparar nociones, categorías o conceptos que se usan en los discursos jurídicos de los casos de estudio.

141 Ibid., p. 292.

142 Pierre LEGRAND, “Sur l'analyse différentielle des juriscultures”, op. cit., p. 1060.

143 Jaakko HUSA, op. cit., p. 1116.

144 Pascal RICHARD, "Les apports de Wittgenstein à la réflexion comparatiste", Revue international de droit_comparé, vol. 57, núm. 4, 2005, pp. 899-920.

145 Silvia DIEZ, op. cit. También: Marcos VAQUER, "La formación de conceptos en el Derecho público: un comentario", Revista Vasca de Administración Pública, núm. especial 99-100, 2014, pp. 3005-3023.

146 Oliver BRAND, "Conceptual Comparisons: Towards a Coherent Methodology of Comparative Law Studies”, Brooklyn Journal of International Law, vol. 32, núm. 2, 2007, pp. 405-466.

147 Reinhart KOSELLECK, historia/Historia, Trotta, Madrid, 3a ed., 2016; y Reinhart KOSELLECK, Historia de conceptos. Estudios sobre semántica y pragmática del lenguaje politico y social, Trotta, Madrid, 2012. 
Es importante destacar que estas propuestas son compatibles con aceptar que los conceptos son constructos que cumplen ciertas funciones (su valor operatorio, es decir, descriptivo, explicativo o heurístico), y que ellas son los que los dota de mayor o menor plausibilidad. Nunca son "puros", sino siempre sesgados por quien lo elabora -sujeto situado históricamente- y, por lo mismo, contingentes. Se trata de mejores o peores propuestas, que deben resultar útiles para la comparación que se emprenda. Un ejemplo de construcción conceptual desde la historicidad e históricamente situada, es el binomio iuspublicidad y iusprivacidad de Velasco ${ }^{148}$.

En este punto se debe tener presente la advertencia de Ponthoreau respecto a la construcción conceptual: "puesto que lo real no existe más que a través de la construcción del investigador, es necesario ser consciente de que no solamente esta construcción resulta una opción del concepteur, sino también que este último no puede deformarla (puesto que ella no existe en sì), mas sí modelarla a su gusto. La finalidad de los modelos oscila entre la explicación y la descripción sin que sus autores sean siempre suficientemente claros sobre los objetivos que buscan. El modelo, puede entonces, asumir una función de legitimación" ${ }^{149}$.

\subsection{Los fines de la comparación de derechos administrativos}

Como se explicó, la razonabilidad de la propuesta argumentativa del comparatista estará condicionada por los objetivos que se plantee, los cuales deberían ser explicitados y justificados. Es decir, el espacio de comparación que se construye el investigador será el que delimite el "espacio de pertinencia" (Legrand) ${ }^{150}$, en el cual, por cierto, no puede caber todo (Ponthoreau) ${ }^{151}$, sino aquello explicitado y justificado en los objetivos de la comparación que se pretenda realizar. De este modo, si bien pareciera razonable hacerse cargo de los problemas presentados el explicar las herramientas metodológicas, la específica forma en la cual se articulen aquellas, debiera constituir el específico marco metodológico con el cual el comparatista se enfrente a la investigación de Derechos administrativos. De este modo evitará simplemente yuxtaponer Derechos positivos, o meramente contrastarlos, para dar lugar a una comparación que sea capaz de aproximarse al fenómeno administrativo real que acontece en el caso que haya decidido estudiar, y en él intentar evidenciar lo que lo identifica o caracteriza.

Si bien cada investigación debe justificarse en fines específicos que la doten de sentido y la articulen, aquellos pueden reflexionarse, a partir de razones, más o menos generales, que actualmente gocen de pertinencia, considerando la larga discusión que sobre la pregunta “¿para qué?” ha desarrollado la teoría del Derecho comparado. Una síntesis de aquel debate, haciéndose cargo de las implicaciones del comparatismo crí-

\footnotetext{
148 Francisco VELASCO, Derecho público más derecho privado, op. cit., pp. 76-80.

149 Marie-Claire PONTHOREAU, Droit(s) constitutionnel(s) comparé(s), op. cit., p. 192.

150 Pierre LEGRAND, "Comparer", op. cit., p. 285.

151 Marie-Claire PONTHOREAU, Droit(s) constitutionnel(s) comparé(s), op. cit., p. 72.
} 
tico, se encuentra en la obra de Ponthoreau ${ }^{152}$. Trasladando dicha reflexión respecto a los Derechos constitucionales a los Derechos administrativos, se podría afirmar que los objetivos de este comparatismo serían, a lo menos, tres:

Primero, permite desarrollar una aproximación crítica del fenómeno administrativo y su manifestación jurídica, lo cual no solo permitirá comprender de forma más leal y profunda al otro, sino que también el Derecho administrativo propio. Esto es así, puesto que seguir el camino del comparatismo crítico implica un proceso autodeconstructivo que, a su vez, conlleva otro deconstructivo de la propia juridicidad doméstica; de ello se sigue su rearticulación o representación mediante un discurso que siempre será dinámico, pues irá cambiando a medida que se avancen las investigaciones. De esta manera, se podrá realizar no solo una contextualización sociojurídica más pertinente del otro; sino que del propio Derecho administrativo doméstico. En otros términos, se vuelve un campo de estudio desde el cual siempre será posible aportar perspectivas nuevas. Así, el Derecho administrativo se vuelve mucho más apasionante.

En segundo lugar, dicho discurso deberá articular las diferencias y similitudes que identifique de los casos que se estudie. Esta articulación permitirá identificar rasgos superficiales y, en especial, la específica expresión que adopta la estatalidad moderna en aquellos. Podrá evidenciar los paradigmas que subyacen a los discursos de los administrativistas, cuáles son sus implicancias y cómo la realidad social específica se proyecta en ellos. Acá, los textos jurídicos oficiales podrán ser solo un punto de partida, ni sus contenidos serán obvios, ni lo que de ellos se diga tampoco. Ser capaces de entender, en los casos que se escojan, la específica política del Derecho administrativo ${ }^{153}$ como su historicidad ${ }^{154}$ permitirá que el comparatismo sirva de contrapeso a los intereses globales homogeneizantes ${ }^{155} \mathrm{y}$ se constituya en un ejercicio respetuoso de comprensión del otro.

Tercero, se renueva la perspectiva sobre los trasplantes o injertos jurídicos, pues su operatividad real mostrará que las lógicas domésticas siempre se imponen, aunque los discursos jurídicos a su respecto no lo evidencien, incluso aunque los términos utilizados sean similares o se traduzcan con una misma palabra. Así, por ejemplo, pueden salir a la luz las implicancias de los discursos sobre la regulación y su impacto en la denominada potestad reglamentaria según la comprensión que de ella se da en España ${ }^{156}$ o Francia ${ }^{157}$. Del mismo modo, se vuelven particularmente problemáticas

152 Ibid., pp. 87-171.

153 Jacques CAILLOSE, La constitution imaginaire de l'Administration, op. cit., p. 11.

154 Sabino CASSESE, La construction du droit administratif. France et Rayaume-Uni, op. cit., p. 9.

155 Marie-Claire PONTHOREAU, "'Global Constitutionalism'. Un discours doctrinal homogénéisant, L'apport du comparatisme critique”, op. cit., p. 125. Pierre LEGRAND, "Comparer”, op. cit., p. 295. Pierre LEGRAND, "Sur l'analyse différentielle des juriscultures”, op. cit., p. 1064 y 1067.

156 Elisenda MALARET, "Un ensayo de caracterización jurídica de una nueva tarea pública: la regulación económica”, Diritto Pubblico, núm. 2, 2008, pp. 535-586 (p. 554).

157 Pierre-Laurent FRIER y Jacques PETIT, Droit Administratif, LGDJ, Paris, 11 a ed., 2017, p. $21,160-163$ y 434. 
ecuaciones de nociones como las de "service public $=$ servicio público = public utilities = servizio pubblico = servicio de interés general"; o el dualismo jurisdiccional colombiano como mero "viaje y aterrizaje" de una idea francesa ${ }^{158}$.

Finalmente, todo lo anterior cobra también una importante consecuencia práctica. Cuando se impulsan reformas administrativas o las llamadas "modernizaciones" del Estado, normalmente se presentan como un argumento a favor de determinadas opciones ciertas fórmulas de derechos extranjeros, lo cual, en medios como el español o el latinoamericano, por su especial receptividad a las construcciones jurídicas foráneas ${ }^{159}$, genera el riesgo de la instrumentalización política de la otredad. Así, el comparatismo crítico, al ser capaz de evidenciarlo o denunciarlo, permite conectar las exigencias democráticas con el quehacer de la academia jurídica. Esto es así, pues, si bien no resulta exigible al debate público los estándares de la investigación comparatista que se desarrolla en las universidades, permitirá plantearse preguntas de trascendencia ética y política: ¿por qué esos casos y no otros?, ¿qué organismo internacional avala la reforma?, ¿qué particularidades domésticas configurarían la práctica jurídica de aquella?, ¿permite aquello que se alcancen los objetivos que el legislador democrático se ha impuesto?, ¿qué hace realmente un jurista cuando explica ante legisladores casos de Derecho extranjero?, etcétera.

\section{CONCLUSIÓN}

En cierto sentido, el comparatismo crítico de Derechos administrativos pretende seguir la senda de Tocqueville. En su clásica obra El Antiguo Régimen y la Revolución, evidenciaba que los discursos jurídicos se apartaban de la realidad social e impedían comprender lo que realmente acontecía ${ }^{160}$, así, detalla cómo aquellos imposibilitaban ver la línea de continuidad entre la burocracia prerrevolucionaria y la que el liberalismo adjudicará como origen del Derecho administrativo moderno ${ }^{161}$. A su juicio, aquello jamás podría ser comprendido por alguien que no haya visto más que la realidad francesa ${ }^{162}$. En resumen, el camino de conocer al otro (realidad ajena), permite conocerse mejor a sí (realidad propia): los horizontes de reflexión se expanden.

De este modo, siguiendo el camino trazado en la introducción, se justificó la posibilidad de comparar Derechos administrativos prescindiendo de discursos homogeneizantes precondicionados epistémicamente, aportando así una crítica (sustanti-

158 Juan Pablo SARMIENTO, Surgimiento de la dualidad de jurisdicciones en Colombia, Editorial Universidad del Norte, Barranquilla, 2012.

159 Silvia DÍEZ, op. cit., p. 185. Diego LOPEZ-MEDINA, op. cit., pp. 344-353. Juan Carlos FERRADA, "Los principios estructurales del Derecho administrativo chileno: un análisis comparativo", Revista de Derecho de la Universidad de Concepción, núm. 221-222, año LXXV, 2007, pp. 99-136.

160 Alexis de TOCQUEVILLE, El Antiguo Régimen y la Revolución, Alianza Editorial, Madrid, $3^{\mathrm{a}}$ ed., 2018, p. 123.

161 Ibid., p. 114.

162 Ibid., p. 64. 
vo) crítica (adjetivo) desde la cual problematizar la globalización neoliberal. Luego, también se señaló su importancia, puesto que aquellos Derechos, en la actualidad, expresan la específica forma en la cual la estatalidad moderna se expresa en lo local, la cual constituye un rasgo clave para la comprensión de la alteridad jurídica. Después, se propuso un conjunto de herramientas metodológicas desde las cuales construir un discurso razonable y razonado, susceptible de ser sometido a crítica, sobre la representación que puede hacer(se) un comparatista de un Derecho administrativo particular.

Realizar un esfuerzo de esta naturaleza tiene, además de las consecuencias políticas y éticas ya explicadas, otras de índole intelectual: exige cuestionar los fundamentos del Derecho administrativo como disciplina (incluso, los fundamentos de aquellos). Siendo una tarea que solo la Universidad, por sus fines propios, puede desarrollar, permite así recuperar su histórico rol subversivo al anquilosamiento de la reflexión: temas se abren o reabren a posibilidades no vistas, ocultas u olvidadas.

En definitiva, para no caer víctima de intereses ocultos o reificaciones de los supuestos, resulta necesario tomarse en serio el Derecho comparado o, más bien, la comparación de Derechos, que, si bien no puede aportar todas las respuestas, ayuda a plantear buenas preguntas. 